\title{
Despite huge investment to contain AMR, recent reports of increased occurrence of superbugs are terrifying
}

\author{
BH Gulumbe ${ }^{1}$ \\ Sri Lankan Journal of Infectious Diseases 2018 Vol.8 (2):69-73 \\ DOI: http://dx.doi.org/10.4038/sljid.v8i2.8217
}

\begin{abstract}
Antimicrobial resistance (AMR) which is considered a significant global health crisis continues to evolve and spread across the globe. If no adequate strategies are put in place to halt its rapid spread, routine surgical and medical procedures would become impossible without effective antimicrobials. By the year 2050, AMR is estimated to cost 10 million lives and about US\$100 trillion annually. Growing concerns due to the escalating spread of multidrug resistant organisms have forced the World Health Organisation (WHO), the Centre for Disease Control and Prevention (CDC), European Commission of the EU, the UK Department of Health and the African Academy of Sciences to put strategies against AMR in place. However, despite efforts to halt AMR, recent reports show disturbing trends of difficult-to-treat deadly infections including gonorrhoea, typhoid, pneumonia, influenza, HIV, malaria and tuberculosis. This article bolsters the need for a comprehensive, real-time and improved surveillance of multidrug resistant organisms, sustained and coordinated action against AMR, development of new antibiotics and vaccines, prevention and control of diseases, improved sanitation and hygiene, sustained research, development of rapid diagnostics as well as provision of affordable and accessible health services.
\end{abstract}

Keywords: Antimicrobial resistance, Multidrug resistant organisms, Antibiotic resistance, $A M R, M D R$

\section{Introduction}

Antimicrobial resistance (AMR) is a major global public health threat. At present, the global annual mortality rate due to AMR is estimated to be 700,000 and by the year 2050 , if no adequate strategies are put in place to halt its rapid spread, it is estimated to cost 10 million lives and about US\$100 trillion annually. ${ }^{1}$ The World Health Organization, the Centre for Disease Control, the Institute of Medicine and the Infectious Diseases Society of America have all declared AMR as a global public health crisis. ${ }^{2}$ There is no doubt that the threat posed by AMR is significant. Unfortunately, many countries of the world are yet to fully recognise how

${ }^{1}$ Department of Microbiology, Faculty of Science, Federal University, Birnin Kebbi, PMB 1157, Kebbi State, Nigeria

Address for correspondence: BH Gulumbe, Department of Microbiology, Faculty of Science, Federal University, Birnin Kebbi, PMB 1157, Kebbi State, Nigeria Telephone: +2347066287090

Email: hgbashar@gmail.com (iD) https://orcid.org/0000-0003-0642-6902

Received 8 May 2018 and revised version accepted 23 July 2018 
significant the threat posed by AMR is. This is evident by the fact that significant gaps have been identified in the area of surveillance, standard methodologies and data sharing especially in Africa and South East Asia as the regions without established AMR surveillance systems. ${ }^{1}$ Although the burden of AMR is more significant in the developing countries with poor sanitation facilities and indiscriminate use of antibiotics in medicine and agriculture, it is a problem that affects every country irrespective of its level of income and development since resistant pathogens are cosmopolitan.

As an evolutionary response to the deadly impact of antimicrobials, microorganisms develop resistance thereby rendering existing antimicrobials ineffective. The development of resistance has resulted in infections becoming more difficult to treat and modern medical interventions becoming more dangerous. ${ }^{3}$ As a result, if appropriate and timely actions are not taken, there is a serious concern that the role of antibiotics in reducing the mortality and morbidity rates of infectious diseases is threatened. ${ }^{1}$

\section{Efforts to tackle the menace of AMR}

Growing concerns due to the escalating spread of superbugs have forced the global health community to put strategies against AMR in place. In 2011, the European strategic action plan on antibiotic resistance developed and put in place strategies to help European member countries address the complex factors that cause AMR. ${ }^{3}$ In order to meet the objectives of this action plan, both the European Commission of the EU and the UK Department of Health came up with their own strategies. The European Commission came up with 12 recommendations against AMR for its member States to implement in 2011. The recommendations were supplemented in 2013, and later updated in 2016. ${ }^{4}$ The UK developed a new and improved 5year AMR strategy covering the period 2013-18, which went beyond that of the European Commission, incorporating aims to increase awareness, promote stewardship of current treatments, and stimulate the development of new treatments. ${ }^{3,5}$ The global community endorsed these strategies for combating AMR and some of the strategies were adopted beyond Europe. The Transatlantic Taskforce on Antimicrobial Resistance (TATFAR) was established in 2011 to enhance Europe and the USA working together against AMR. ${ }^{6}$ Similarly a number of recommendations have been published on tackling the spread of AMR. ${ }^{7}$ Additionally, to help hospitals promptly identify drug resistant infections and halt their spread, the CDC has in 2016 set up a country-wide laboratory network. ${ }^{8}$ The African Academy of Sciences and the South African Medical Research Council announced a research investment of \$2 million to tackle resistance in 2018.

Despite these efforts and recommendations and increasing political will to halt AMR, it continues to evolve and spread globally. ${ }^{9-13}$

However, in comparison with developed regions such as Europe and US, African and South East Asian regions have not put adequate strategies in place to combat AMR. In these regions, the problem of AMR is not only understudied, but also aggravated by factors such as high rate of infections, suboptimal disease surveillance programs, lack of AMR stewardship, and importantly, indiscriminate use of antibiotics. ${ }^{1,14-16}$ Additionally, in many developing countries, healthcare facilities are lacking and where available, they are mostly in dilapidated conditions characterised by inadequate diagnostic capacity and lack of reliable supply of reagents, leaving the population with limited access to formal healthcare services. ${ }^{17}$ To make the situation even worse, drug retailers some of whom with no form of medical training, diagnose and prescribe all sorts of antibiotics. Patients patronise them since they are cheaper, 
quick to access and offer negotiable health services. Some remote communities have these types of facilities as the only available health facilities. By implication, inadequate laboratory diagnosis means that resistant pathogens go undetected, untreated and may continue to be spread. In many cases, diseases due to resistant pathogens are detected only when treatment failure became eminent. ${ }^{15}$

\section{Difficult-to-treat superbugs are on the increase globally}

Resistance shown by some potentially life-threatening infections to even last resort antibiotics is alarming. In 2017, the European Centre for Disease Prevention and Control (ECDC) report on antimicrobial resistance showed increasing trend of antimicrobial resistance among various bacterial pathogens. A noteworthy observation is that the overall resistance rates among $E$ coli isolates skyrocketed from 2013 to $2016 .{ }^{9}$ For the second consecutive year, a high percentage of carbapenems, aminoglycosides, and fluoroquinolones resistant Acinetobacter species were isolated from Baltic countries as well as southern and south-eastern Europe. Acinetobacter spp have been linked to drug resistant pneumonia. ${ }^{9}$ Additionally, resistance has been reported in deadly diseases such as influenza, HIV, malaria, tuberculosis, and gonorrhoea. ${ }^{18}$ A 2017 WHO report on AMR indicates that difficult-to-treat gonorrhoea is on the increase in 77 countries. ${ }^{19}$ Endemic typhoid caused by an extensively drug-resistant (XDR) Salmonella Typhi strain heightened worries that the viability of treating such infections, particularly in developing countries will be highly limited or even impossible, leading to the possible re-emergence of pre-antibiotic era when typhoid was a death sentence. ${ }^{20}$

A recent WHO report published in January, 2018 indicated that terrifying high levels of AMR was found worldwide. ${ }^{13}$ In Korea, increased incidence of TEM-135 $\beta$-Lactamase-producing Neisseria gonorrhoeae has recently been documented. ${ }^{21}$ In 2017, the Centre for Disease Control identified more than 220 cases of drug resistant bacteria that were not only resistant to almost all available drugs, but also capable of spreading antibiotic resistant genes. These types of superbugs are especially deadly in people with impaired immune system and up to $50 \%$ of infection with such bacteria are fatal. ${ }^{8}$ An estimated 2 million Americans fall sick due to these terrifying superbugs. In Africa, a high level of multidrug-drug resistant bacteria to frequently prescribed antibiotics have been documented in a recent systematic review. ${ }^{1}$ Sometime in March this year, the UK government agency, Public Health England, in a press release, announced an extreme case of high level resistant gonorrhoea for the first time being resistant to a combination of azithromycin and ceftriaxone. This had sparked serious fear.

These rapid and widespread cases of difficult-to-treat infections indicate limited antimicrobial treatment options and further indicate superbugs are on the verge of taking over. The CDC principal deputy director, Anne Schuchat, once said, 'as fast as we run to tackle antibiotic resistance, some microbes have moved fast ahead of us'. ${ }^{8}$ The director of WHO's Antimicrobial Resistance Secretariat, Dr Marc Sprenger, recently said reports of worldwide high level antimicrobial resistant superbugs confirm a serious situation. ${ }^{13}$

\section{Conclusion}

The problem of AMR may continue to linger since the issue of widespread consumer abuse of antibiotics, which is a major driver of AMR is very difficult (though not impossible) to confront, especially in remote localities of developing countries with no health facilities. To prevent superbugs from taking over, it is necessary to come up with sustainable local and international interventions. The World Health Organisation has warned that AMR is a major 
global health crisis that must be urgently tackled through coordinated action. ${ }^{18} \mathrm{~A}$ comprehensive, real-time and improved surveillance of AMR at both international and national levels are necessary. The traditional practice of prescribing antibiotics before diagnostic outcome, must stop. Equally, the search for new antibiotics and development of vaccines must continue. $^{22,23}$ The United Nations has recognised that prevention and control of diseases in both humans and animals, improved sanitation and hygiene, sustained research and development, development of rapid diagnostics, affordable and accessible health services, enhanced capacity-building and technology transfer, as keys to tackling AMR. ${ }^{24}$

\section{References}

1. Tadesse, B. T., Ashley, E. A., Ongarello, S. et al., Antimicrobial resistance in Africa: a systematic review. BMC Infect Dis, 2017; 17:1-17. doi: http://dx.doi.org/10.1186/s12879-0172713-1

2. Bryan, C. A. O., Crandall, P. G. and Ricke, S. C., Antimicrobial resistance in foodborne pathogens. In: Food and Feed Safety Systems and Analysis, Elsevier Inc, 2018; p97-115. doi: http://dx.doi.org/10.1016/B978-0-12-811835-1.00006-3

3. Wells, V. and Piddock, L. J. V., Addressing antimicrobial resistance in the UK and Europe. Lancet Infec. Dis, 2017; 3099:1-2. doi: http://dx.doi.org/10.1016/S1473-3099(17)30633-3

4. European Commission. A European one health action plan against antimicrobial resistance (AMR). Brussels; European Commission, 2017 https://ec.europa.eu/health/amr/sites/amr/files/amr_action_plan_2017_en.pdf

5. WHO. World Malaria Report. In. Edited by WHO. 2015. Available at: http://apps.who.int/iris/bitstream/10665/200018/1/9789241565158_eng.pdf?ua=1.Switzerland, Geneva.

6. Do, N.T.T, Ta, N.T.D., Tran, N.T.H et al., Point-of-care C-reactive protein testing to reduce inappropriate use of antibiotics for non-severe acute respiratory infections in Vietnamese primary health care: a randomised controlled trial. Lancet Glob Health, 2016; 4:e633-41. doi: https://doi.org/10.1016/S2214-109X(16)30142-5

7. O'Neill, J. Tackling drug-resistant infections globally: Final Report and Recommendations. 2016. Available at: http://amr-review.org/Publications

8. Szabo, L., Nightmare bacteria widespread in U.S hospitals. Scientific American 2018. Available at: https://www.scientificamerican.com/article/nightmare-bacteria-widespread-in$u$-s-hospitals

9. Soucheray, S., Latest European data show increasing antibiotic resistance. 2017. Available at: http://cidrap.umn.edu/news-perspective/2017/11/latest-european-data-show-increasingantibiotic-resistance

10. Robinson, T.P., Bu, D.P., Carrique-mas, J. et al., Antibiotic resistance is the quintessential One Health issue. Trans R Soc Trop Med Hyg, 2016; 110:377-380 doi: http://dx.doi.org/10.1093/trstmh/trw048

11. Williams, P.C. M., Isaacs, D. and Berkley, J.A., Review: Antimicrobial resistance among children in sub-Saharan Africa. Lancet Infect Dis, 2017; 3099:1-12. doi: http://dx.doi.org/10.1016/S1473-3099(17)30467-X

12. Williamson, D.A., Lane, C., R., Easton, M. et al. Increasing antimicrobial resistance in nontyphoidal salmonella isolates in Australia from 1979 to 2015. AMR Salmonella from Aust. Antimicrob. Agents Chemother, 2018; 66(2):1-9. doi: https://doi.org/10.1128/AAC.02012-17

13. WHO. High level of antibiotic resistance found worldwide, new data shows. 2018. Available at: http://www.who.int/mediacentre/news/releases/2018/antibiotic-resistance-found/en/

14. Bouamri, M.C.El, Arsalane, L., Kamouni, Y. El. Et al., Antimicrobial susceptibility of urinary Klebsiella pneumoniae and the emergence of carbapenem-resistant strains: A retrospective study from a university hospital in Morocco, North Africa. African J Urol, 2015; 21:36-40. doi: http://dx.doi.org/10.1016/j.afju.2014.10.004

15. Kariuki, S. and Dougan, D., Antibacterial resistance in sub-Saharan Africa: an underestimated emergency. Ann N Y Acad Sci, 2014; 1323:43-55. doi: https://doi.org/10.1111/nyas.12380. 
16. Karuniawati, A., Saharman, Y. and Lestari, D., Detection of carbapenemase encoding genes in Enterobacteriace, Pseudomonas aeruginosa, and Acinetobacter baumanii isolated from patients at Intensive Care Unit Cipto Mangunkusumo Hospital in 2011. Acta Med Indones, 2013; 45:1-106. No doi

17. Okeke, I., Aboderin, O., Byarugaba, D. et al., Growing problem of multidrug-resistant enteric pathogens in Africa. Emerg Infect Dis, 2007; 3:1640-1646. doi: https://doi.org/10.3201/eid1311.070674

18. Taylor, R., Tackling Drug-Resistant Infections Globally. House of Lords Library Notes. 2016. https://researchbriefings.parliament.uk/ResearchBriefing/Summary/LLN-20160044\&ved=2ahUKEwip9D_nordAhXIK8AKHbY5BgcQFjAAegQICBAB\&usg=AOvVaw3YTNA602ljgMymSvSWR $\mathrm{cm} 4$

19. WHO. Antibiotic-resistant gonprrhoea on the rise, new drugs need. 2017. Available at: http://www.who.int/mediacentre/news/releases/2017/Antibiotic-resistant-gonorrhoea/en/

20. Levine, M. and Simon, R., The Gathering Storm: Is untreatable typhoid fever on the way? MBio, 2018; 9: 1-4. doi: https://doi.org/10.1128/mBio.00105-18

21. Rim, J.H., Kim, H., Lee, H. et al., Recent increase in the incidence of TEM-135 $\beta$-Lactamaseharboring Neisseria gonorrhoeae in Korea. Ann Lab Med, 2018; 38:324-330. doi: https://doi.org/10.3343/alm.2018.38.4.324

22. Clift, C. and Salisbury, D.M., Enhancing the role of vaccines in combatting antimicrobial resistance. Vaccine, 2017; 35:6591-6593. doi: https://doi.org/10.1016/j.vaccine.2017.09.053

23. Jansen, K. U., Knirsch, C. and Anderson, A. S., The role of vaccines in preventing bacterial antimicrobial resistance. Nat Med, 2018; 24(1):10-20.

doi: https://doi.org/doi:10.1038/nm.4465

24. United Nations. Draft political decleration of the high-level meeting of the General Assembly on Antimicrobial resistance. 2016. Available at: https://www.un.org/pga/71/wpcontent/uploads/sites/40/2016/09/DGACM_GAEAD_ESCAB-AMR-Draft-Political-

Declaration-1616108E.pdf 